\title{
VEINTICINCO AÑOS DE RELACIÓN ENTRE LA INFORMÁTICA $Y$ LOS DERECHOS AL HONOR Y A LA INTIMIDAD PERSONAL Y FAMILIAR
}

\author{
LUCRECIO REBOLLO DELGADO \\ ProfesorTitular de Derecho Constitucional \\ de la UNED
}




\section{SUMARIO}

1. INTRODUCCIÓN. 2. LA REGULACIÓN CONSTITUCIONAL DE LA PROTECCIÓN DE DATOS.

3. El-DESARROLLO LEGISLATIVO. 4. LOS CONDICIONANTES NORMATIVOS EXTERNOS.

5. APORTACIÓN DEL TRIBUNAL CONSTITUCIONAL A LA INTERPRETACIÓN DEL ARTICULO 18.4 CE. 6. CONCLUSIONES. 


\title{
VEINTICINCO AÑOS DE RELACIÓN ENTRE LA INFORMÁTICA Y LOS DERECHOS AL HONOR Y A LA INTIMIDAD PERSONAL Y FAMILIAR
}

\author{
POR \\ LUCRECIO REBOLLO DELGADO \\ ProfesorTitular de Derecho Constitucional \\ de la UNED
}

\section{INTRODUCCIÓN}

El conocimiento que el Estado ha tenido históricamente del ciudadano es sumamente escaso hasta la Revolución Francesa de 1789. Suele concretarse en aspectos tributarios o de prestación de determinados servicios, con un ámbito muy localizado y con una escasa capacidad de difusión e intercambio. Era mayor, como apunta FROSINI ${ }^{1}$ el ejercido por «...la Iglesia quien, por el contrario, llevaba un registro de sus fieles, a partir de la inscripción de su bautismo, matrimonio, defunción, etc.". Tampoco es de tener en cuenta, en estas épocas, la capacidad de intromisión del propio ciudadano en la íntima parcela de los

1 FrosinI, V., "Bancos de datos y tutela de la persona", Revista de Estudios Políticos, $\mathrm{n}^{\circ} 30$ de 1982, pág. 68. 
demás. Es el Estado, fundamentalmente por la necesidad estadística, quien primero va a suscitar la problemática del acopio de datos y su influencia en los reconocidos ya, derechos de la personalidad.

Las nuevas tecnologías, al posibilitar la racionalización, simplificación, celeridad y seguridad de las prácticas administrativas y de recopilación de datos, se presentan como una exigencia inaplazable para cualquier Estado que no desee vivir de espaldas al progreso. Ahora bien, el uso de los modernos medios electrónicos, estén en manos de quien estén, contraen el riesgo de injerencia en la vida privada, tienen implícita la posibilidad de lesionar derechos.

La informática debidamente ordenada y accesible, constituye indefectiblemente poder, y no cabe duda de que al Estado le es necesaria determinada información para cumplir sus fines. Pero no es menos cierto que un uso abusivo o incontrolado de ella puede minar el funcionamiento de cualquier Estado. El mismo riesgo de acumulación de datos, al que está sometido el individuo por la acción del Estado, se corre con la acumulación de datos por parte de otros ciudadanos.

De todas las circunstancias apuntadas es consciente nuestra vigente Constitución, si bien desde su promulgación han variado bastantes aspectos que conviene tener en cuenta. No habiendo variado el texto constitucional, su evolución interpretativa y aplicativa es sustantiva, y como veremos en las siguientes páginas, el artículo 18.4 ha sido útil para la protección jurisdiccional civil, así como para un desarrollo legislativo acorde a las necesidades actuales, tanto desde el punto de vista informático, como de protección de derechos.

Se pretende en este artículo, repasar el contenido y evolución constitucional y el desarrollo legislativo y jurisprudencial de este ámbito jurídico tan esencial en la actualidad, y en aras de la claridad se sigue un orden cronológico.

\section{LA REGULACIÓN CONSTITUCIONAL DE LA PROTECCIÓN DE DATOS}

La CE no ha sido ajena a la importancia que de forma genérica la tecnología, y de forma concreta la informática, está produciendo en las relaciones sociales y en la persona. Esta situación de la que ahora somos conscientes, había sido anticipada por mentes lúcidas, como es 
el caso de RUIZ-GIMÉNEZ², que ya en 1969 manifestaba lo siguiente: "si la intimidad es un valor fundamental del ser del hombre, uno de sus bienes básicos, no cabe duda de que ha de reflejarse en la existencia colectiva como un derecho natural o fundamental, que el ordenamiento jurídico debe proteger contra cualquier violación por parte de los demás hombres, y más aún de las instituciones o comunidades que éstos forman».

La predicción del citado autor, era anterior incluso, a inquietudes semejantes en otros ordenamientos. Ninguna de las constituciones vigentes en Europa, en la fecha que hemos referenciado, había previsto situaciones de vulneración de derechos de la persona por medio o a través de los modernos medios tecnológicos. Era frecuente, cuando en contadas ocasiones surgían los conflictos, acudir a laboriosas interpretaciones doctrinales o jurisprudenciales de determinados contenidos de las constituciones.

Hasta 1970, en el Länd de Hesse, no surgirá una normativa concreta de protección. En 1974 surge en Estados Unidos la Privacy Act. Pero la primera ley realmente orgánica y completa sobre protección de la intimidad y sobre el control de los bancos de datos no se dará hasta 1973, en el Parlamento sueco ${ }^{3}$. En el mismo año, el Consejo de Europa adopta la resolución $n .^{\circ} 22$ sobre «la protección de la vida privada de las personas físicas respecto a los bancos electrónicos de datos en el sector privado" y en 1974 se amplía a los datos del sector público.

Estos considerables antecedentes normativos constituían una importante premisa de carácter jurídico y político para un acercamiento serio a las relaciones entre el ciudadano y la Administración Pública, que tuviese en cuenta adecuadamente el progreso tecnológico.

La Constitución de Portugal de 1977 enuncia por primera vez con rango constitucional el principio por el cual cada ciudadano tiene el derecho a conocer sus datos personales recopilados en los bancos, $y$ de pretender su corrección y actualización (art. 35). La incidencia de este artículo, así como las diversas leyes sobre protección de datos personales, influyen en la idea de nuestro constituyente al respecto de la necesidad de regulación de un ámbito tan significativo ya en 1978, como el de la informática. Por ello, el borrador y en el Anteproyecto

2 RUIZ-GIMÉnEZ, J., «El derecho a la intimidad», Cuadernos para el Diálogo, n. ${ }^{\circ} 66$ de 1969, pág. 10.

3 Datalagen, de 11 de mayo de 1973. 
Constitucional establecía que "La ley limitará el uso de la informática para garantizar el honor y la intimidad personal y familiar de los ciudadanos» ${ }^{4}$. Este texto, con algunas modificaciones, pasó a ser el art. 17 del Informe de la Ponencia. En la Comisión del Congreso, surgieron dos posturas al respecto del contenido del citado artículo; una primera ${ }^{5}$, pretendía la supresión del apartado $4 .^{\circ}$ del art. 17 (art. 18.4 vigente), entendiendo que la protección que se proporcionaba con el contenido del apartado primero (art. 18.1 actual), preveía cualquier tipo de atentado contra tales facultades. También considera inoportuno, esta postura, hacer una mención expresa a la informática y no a otra serie de técnicas o medios que también pueden ir contra la intimidad, el honor o la propia imagen. La segunda postura ${ }^{6}$, considera como muy conveniente hacer mención expresa de la informática, pero haciendo extensiva la tutela frente a cualquier derecho, por un uso indebido, $y$ no sólo a los derechos de la personalidad. Como puede comprobarse en el texto del artículo 18.4, la segunda postura fue la que tuvo reflejo constitucional.

De esta forma, la CE de 1978, siguiendo la intencionalidad, que no la literalidad de la Constitución Portuguesa de 1977, regula la utilización informática. Establece, como afirma ÁLVAREZ CONDE7 que «el reconocimiento de estos derechos fundamentales efectuado por el art. 18.1 debe ser considerado como una manifestación concreta del derecho a la integridad moral del art. 15 de la CE». De esta forma tangencial, el art. 18.4 de nuestra norma fundamental remite al desarrollo legislativo la limitación del uso de la informática para evitar la colisión directa entre el derecho a la intimidad con las necesidades informáticas, fundamentalmente de los poderes públicos.

También tiene implicaciones informáticas el art. 105.b de la CE, el cual posibilita el acceso de los ciudadanos a los archivos y registros administrativos, salvo en lo que afecte a la seguridad y defensa del Estado, averiguación de los delitos y la intimidad de las personas.

Afirma FROSINI ${ }^{8}$ que "la nueva relación que se estableció entre los ciudadanos, y entre los ciudadanos y el Estado... planteó de nue-

\footnotetext{
Anteproyecto Constitucional. B.O.C. de 5 de enero de 1978.

Defendida por el Sr. Sancho Rof.

Sustentada por el Sr. Gastón Sanz y apoyada por el Sr. Roca Junyent.

7 Álvarez Conde, E., Curso de Derecho Constitucional, vol. I, Madrid, 1992,
} pág. 294.

8 Obra citada, págs. 32 y 33. 
vo el problema fundamental de cómo reglamentar la relación entre poder y libertad", ante ello, sigue manifestando el autor, se pueden dar dos posturas; "una seguida por la legislación americana que se concreta en el principio de que todo está permitido, salvo lo que está prohibido, y otra cuyo representante principal es Alemania, la cual entiende que cualquier actividad relativa al procesamiento de datos personales está prohibida, salvo cuando está permitida».

No parece descaminado pensar que la regulación que afecta a la protección de datos en España, está inmersa en la segunda de las dos opciones citadas. No cabe duda, que el constituyente perdió, una magnífica oportunidad de una ex novo y original regulación al respecto del tratamiento automatizado de datos. Significativo de lo manifestado, es el distinto enclave constitucional de los dos artículos citados. Por una parte, el art. 18.4, se inserta dentro del núcleo dogmático de la Constitución (Sección Primera del Capitulo Segundo del Título I), correspondiéndole por tanto, el mayor grado de protección. Por contra, el contenido de mayor virtualidad, en el ámbito de salvaguarda de derechos, es decir el art. 105.b, se sitúa en la parte orgánica de la $C E$, quedando con ello difuminados sus elementos garantizadores y protectores. Además, su contenido, no deja de identificarse con el del art. 20.1.d). Con todo, el reconocimiento constitucional que es leve e inconcreto, queda pendiente de una normativa posterior, que a pesar de ser orgánica, en virtud del art. 81 del propio texto, queda apartada del carácter constitucional.

En definitiva, no podemos dejar de tener en cuenta las afirmaciones delTribunal Constitucional, que a nuestro entender resumen de forma acertada la intencionalidad del constituyente, cuando manifiesta al respecto del art. 18.4, que «...De este modo, nuestra Constitución ha incorporado una nueva garantía constitucional, como forma de respuesta a una nueva forma de amenaza concreta a la dignidad y a los derechos de la persona, de forma en último término no muy diferente a como fueron originándose e incorporándose históricamente los distintos derechos fundamentales...n ${ }^{9}$.

En las relaciones entre informática y derecho, la aceleración que se ha producido es muy significativa, y hasta en ocasiones impropia de la naturaleza de las normas, que pretenden de forma genérica su permanencia en el tiempo. Así pues, se habla ya de diversas generaciones o fases en la garantia jurídica de los datos, a imagen y seme-

9 STC 254/93, fundamento jurídico sexto. 
janza de las generaciones de ordenadores y de las denominadas generaciones de derechos. De esta forma, pueden distinguirse tres fases con claridad: una primera generación requiere la autorización previa de los bancos de datos; la segunda generación, coincide con la garantía de los que con posterioridad han sido denominados datos sensibles, dada su incidencia en los derechos de la personalidad; y por último, una tercera generación, que atiende a la imposibilidad de un control previo de los equipos, y de un control estático de los datos, y por tanto, que tiene que prevenir su potencialidad y funcionalidad.

En la virtualidad protectora del art. 18.4 de la $C E$, de nuevo surgen las discrepancias doctrinales a la concepción que de este precepto debe realizarse. Como bien sabemos, el derecho a la intimidad informática, ve la luz a través de la sentencia del Tribunal Federal Alemán de 15 de diciembre de 1983, por la cual se adecua el concepto de derecho a la autodeterminación informativa. En España, LUCAS MURI$\mathrm{LLO}^{10}$, introduce el término vía art. 18.4 de la CE, manifestando que el derecho a la intimidad normalmente implica el poder jurídico de rechazar intromisiones ilegítimas en la esfera protegida, y correlativamente, determinar de forma libre, la propia conducta. Es un típico derecho de defensa. Pero para el autor que venimos resumiendo, la técnica de protección de datos, es más compleja. Por ello, es necesario abandonar el concepto clásico de derecho a la intimidad y optar por la creación de uno nuevo (el derecho a la autodeterminación informativa), que tendría como objeto, preservar la información individual, frente a su utilización incontrolada. De esta forma el derecho a la intimidad se subdividiría en una intimidad física o clásica, y en una intimidad informativa, entendida ésta, como el derecho a determinar cómo y en qué medida se puede comunicar a otros, información sobre uno mismo.

Pese a todo, no parece ser esta la visión mayoritaria de la doctrina, ni de la jurisprudencia, que entienden al derecho a la intimidad como universalmente aplicable frente a cualquier tipo de agresión, violación o intromisión, provenga esta de donde provenga. Tampoco faltan autores ${ }^{11}$ que entienden la construcción del Tribunal Federal Alemán como propia de un sistema, cuya Carta Magna no recoge de forma expresa el derecho a la intimidad. De esta forma, la construcción jurídica es lógica en Alemania, pero no lo es tanto en un sistema como el

10 LuCAS MuRilLo de LA CUEVA, P., El derecho a la autodeterminación informativa, Tecnos, Madrid, 1990, págs. 117 y ss.

11 RUIz MigueL, C., La configuración constitucional del derecho a la intimidad, Tecnos, Madrid, 1995, pág. 95. 
español en que se recogen de forma expresa por la Constitución diversas manifestaciones del derecho a la personalidad, como son el honor, la propia imagen y la intimidad personal y familiar.

Resumiendo, no podemos realizar otra aseveración más que aquella que entiende al art. 18.4 como una indicación expresa del contenido esencial del derecho a la intimidad. Ello tiene un pleno acoplamiento en nuestro ordenamiento jurídico en cuanto a concepción, idea y grado de garantía del derecho. En definitiva, el derecho a la intimidad informática, es una extensión de un derecho raíz y con pleno asentamiento en el derecho a la intimidad personal y familiar, con implicaciones en el derecho al honor y a la propia imagen.

De esta forma, parece claro, que todo ordenamiento jurídico ha de establecer un umbral de tutela de la información personal frente a los peligros que representa la informática. Estos principios básicos fueron establecidos por la Comisión de Estudio sobre la Protección de la Intimidad ${ }^{12}$, los cuales se resumen en tres apartados básicos:

1. Todo individuo tiene derecho a acceder a la información personal que le afecte, y especialmente a aquella que se encuentra en bancos de datos informatizados.

2. Todo individuo ha de tener la posibilidad y el derecho a controlar, de forma razonable, la transmisión de la información personal que le afecte.

3. La norma ha de regular necesariamente, como garantía del derecho a la intimidad:

- El tiempo durante el que se pueden conservar los datos personales.

- La determinación de los fines a que obedece la creación del fichero.

- Garantías para hacer efectiva la calidad de los datos personales (veracidad, integridad y actualidad).

- Prohibición de la revelación de datos personales.

Partiendo de la idea, de que utilizamos el concepto de protección de datos, para referirnos a la uprotección jurídica de las personas en lo que concierne al tratamiento automatizado de sus datos persona-

12 Comisión creada en Estados Unidos en 1974, en virtud del contenido de la Privacy Act del mismo año. 
les»13, llegamos a la conclusión, que la pretensión primera del legislador ha de pasar necesariamente por proteger a las personas ante el manejo o manipulación, no autorizada, de sus datos personales, siempre que los datos, sean susceptibles de un tratamiento informático.

También se nos hace necesaria la definición nítida del concepto de dato. Así identificamos dato con documentación, con un contenido aislado y sin relación con nada. Si sometemos el dato o datos a un tratamiento o adecuación a un fin, con objeto de obtener un resultado concreto, el dato se convierte en información.

Pese a lo manifestado hasta ahora, no debemos olvidar que aún siendo el ámbito principal de protección del art. 18.4 la intimidad, el inciso final del mismo, garantiza también "el pleno ejercicio de sus derechos".

\section{EL DESARROLLO LEGISLATIVO}

En España, hasta 1992, se articuló un sistema que sin duda no obedecía a ninguna de las generaciones mencionadas. La protección del contenido del art. 18.4 de la C.E. se brindaba en base a la Ley Orgánica $1 / 1982$. Se pensaba que con la protección civil del derecho al honor, la intimidad y la propia imagen, era suficiente para solventar las intromisiones o violaciones que pudiera producir la informática. Por ello, la Disposición Transitoria Primera de la citada ley, establecía que «...en tanto se promulge la normativa prevista en el art. 18 , apartado $4 .^{\circ}$, de la Constitución, la protección civil del honor y la intimidad personal y familiar frente a las intromisiones ilegítimas derivadas del uso de la informática se regulará por la presente ley". Pese a ello, y como acertadamente resume Lucas Murillo, «la Ley Orgánica 1/1982 solamente protege lo que podríamos llamar el ámbito más estricto de la intimidad, pero no sirve para impedir la captación, el acopio, revelación y transmisión de informaciones personales que no necesariamente han de pertenecer a ese reducto último de la vida privada. Por lo demás, no es útil para brindar al afectado medios que le permitan conocer qué datos relativos a su persona usan terceros, ni para permitirle rectificar los que sean inexactos o cancelar los que carezcan de toda relevancia actual' ${ }^{14}$.

13 Ésta es la definición que ofrece DaVARA, M. A., en su obra Derecho Informático, Aranzadi, Madrid, 1993, pág. 49.

14 LuCAS MuRILLO DE LA CUEVA, P., Informática y protección de datos personales, Centro de Estudios Constitucionales, Madrid, 1993, pág. 17. 
El primer desarrollo normativo específico del art. 18.4, no llegará hasta 1992, fecha en que es promulgada la denominada LORTAD (Ley Orgánica de Tratamiento Automatizado de Datos de Carácter Personal). Nace esta norma con el fin de uhacer frente a los riesgos que para los derechos de la personalidad puede suponer el acopio y tratamiento de datos por medios informáticos.... ${ }^{15}$.

También conviene recordar que la LORTAD no estaba llamada a solventar o prevenir todos y cada uno de los derechos de los que un ciudadano puede ser titular, sino que lo es fundamentalmente en aqueIlos que la informática puede lesionar, es decir, los referidos a la personalidad, aunque no a todos. Se deduce de una lectura somera del texto, que el derecho a la propia imagen es absorbido, desde la perspectiva de la protección de datos por el derecho al honor, y éste se protege con levedad. Así cabe la prevención del honor, únicamente, en la medida que el acopio de datos y su adecuación y ordenación, pueden ofrecer el perfil de una persona, o configurar una determinada reputación o fama que puede verse lesionada.

Los ordenamientos jurídicos europeos han entendido como sumamente funcional y efectiva la institucionalización de un órgano independiente que controle toda la actividad relacionada con el tratamiento de datos. Esta idea, que parte del ordenamiento jurídico estadounidiense, se instaura en el ordenamiento jurídico español con plena garantía de efectividad. EI Título VI de la LORTAD, configura la Agencia de Protección de Datos como un ente de Derecho Público, con personalidad jurídica propia y plena capacidad pública y privada, y que actúa con plena independencia en el ejercicio de sus funciones. La Disposición Final primera de la LORTAD habilita al Gobierno para dictar las disposiciones necesarias para la aplicación, desarrollo y regulación de la estructura orgánica de la Agencia de Protección de datos. En virtud de ésta delegación legislativa, surge el Real Decreto 428/1993 por el que se aprueba el Estatuto de la Agencia de Protección de Datos. Se dota a esta institución de potestad normativa (informa los proyectos de disposiciones que afecten al tratamiento de datos, tiene potestad para realizar Instrucciones y Recomendaciones, para adecuar los tratamientos automatizados a los principios de la LORTAD). También se establecen especiales garantías para el nombramiento y la permanencia de los cargos directivos, los cuales tienen su origen en un órgano colegial, como es el Consejo Consultivo. Otro elemento de garan-

15 Exposición de Motivos de la LORTAD, apartado segundo. 
tía de independencia, lo constituye el aspecto financiero, si bien aquí, ha de manifestarse, que la Agencia carece de fuentes de financiación propias, dependiendo de los Presupuestos Generales del Estado, pese a éllo, la Agencia elabora un anteproyecto de presupuesto anual. Por último, podemos entender como elemento de garantía de independencia, la capacidad de relación que tiene la Agencia con otros órganos de la Administración. Aunque las relaciones Agencia-Gobierno, han de realizarse a través del Ministerio de Justicia, ello no es óbice, para que la Agencia tenga acceso directo a cualquier órgano, de cualquier Administración Pública. La Agencia se relaciona también con las Cortes Generales, mediante la presentación de una memoria anual.

En definitiva, puede manifestarse, que el legislador español de 1992 (LORTAD) y de 1993 (Real Decreto 428/1993) se anticipa al contenido del art. 28 de la Directiva 95/46/CE, que obliga al establecimiento de una autoridad de control, encargada de vigilar la aplicación de las normas relativas al tratamiento de datos de carácter personal, si bien esta última norma tiene algunas repercusiones sobre todo en el funcionamiento de la Agencia, de que serán analizadas con posterioridad al estudio que ahora abordamos, y que hace relación a las funciones de la Agencia de Protección de Datos.

En diciembre de 1999 se promulga la Ley Orgánica 15/1999, de Protección de Datos de Carácter Personal, que deroga la LORTAD. Su objeto es, como establece el art. 1 "garantizar y proteger en lo que concierne al tratamiento de datos de carácter personal, las libertades públicas, los derechos fundamentales de las personas físicas, y especialmente de su honor e intimidad personal y familiar". Como fácilmente puede apreciarse, existe una inversión de las prioridades que establece el art. 18.4. Ya no es únicamente la intimidad, honor y propia imagen la que se puede lesionar, sino que lo son todos los derechos de la persona, si bien éstos citados de forma especial.

Otra característica que presenta la Ley Orgánica que venimos citando, la constituye la incorporación en esencia de los contenidos troncales de la LORTAD, si bien, pulidos algunos aspectos que chocaban con la normativa europea, e incluso con contenidos de la $\mathrm{CE}^{16}$.Incluso, ha existido una reciente proposición de Ley Orgánica presentada por el Grupo Parlamentario Socialista, con objeto de modificar algunos aspectos de la misma ${ }^{17}$.

16 Se hace referencia de éstos en el apartado 5 de este artículo.

17 BCG n. ${ }^{\circ} 233$, de 26 de abril de 2002. 
Pese a las circunstancias apuntas, cabe resumir que el desarrollo legislativo del art. 18.4 es acorde con el contenido general de nuestra Constitución, con el ordenamiento jurídico europeo, y que se coloca a la cabeza de los ordenamientos que en mejor y mayor medida ofrecen una protección específica de los datos de carácter personal. Las herramientas jurídicas son las adecuadas, pese a ello, no debemos olvidar lo mudable de las posibilidades técnicas. Para realizar una adecuación de las normas a la realidad y a la actualidad, es imprescindible en los ordenamientos jurídicos modernos la actuación de la jurisprudencia constitucional. En ella recae la tarea de hacer elástica las normas, y en especial la Ley orgánica 15/1999.

\section{LOS CONDICIONANTES NORMATIVOS EXTERNOS}

Como hemos apuntado, la inquietud de las organizaciones supranacionales por el respeto a los derechos de la personalidad, así como por las disfunciones sociales que los nuevos medios tecnológicos pueden producir, tuvo su plasmación en el Convenio $n .^{\circ} 108 \mathrm{del}$ Consejo de Europa ${ }^{18}$. Este texto establece una serie de principios básicos para la protección de datos, señala criterios que regulan su flujo y crea un Comité Consultivo a quien se encomienda la formulación de propuestas para mejorar la aplicación del Convenio.

Su contenido, puede resumirse en base a los principios que establece, los cuales se entienden como imperativos para aquellos Estados que lo ratifican. Tienen la genérica pretensión, como indica la Introducción del propio Convenio de ureforzar la protección de datos, es decir, la protección jurídica de los individuos con relación al tratamiento automatizado de datos de carácter personal que les conciernen".

También conviene hacer referencia al Acuerdo de Schengen de 14 de junio de $1985^{19}$. Tiene como centro de su contenido disposiciones de los órganos de la Unión Europea relativos a la supresión gradual de los controles en las fronteras comunes. No obstante, los artículos 7 y 9 del citado Acuerdo pretenden la coordinación entre Estados, al efecto de controlar y facilitar «los datos que puedan ser de interés para las otras partes en la lucha contra la criminalidad" (art. 9). En defi-

18 Ratificado por España el 27 de enero de 1984 (BOE n..$^{\circ} 274$, de 15 de noviembre de 1985).

19 BOE n..$^{\circ} 181$ de 30, de junio de 1991. 
nitiva, el Acuerdo de 1985 es un elemento de coordinación interestatal, que afecta al tratamiento y protección de datos, aunque no tenga un carácter concreto como lo tiene el Convenio de 1981, o la Directiva 95/46 del Parlamento Europeo y del Consejo, al respecto del tratamiento de datos personales.

El Acuerdo de Schengen no deja de ser un paso más en el contenido del art. 12 del Convenio de 1981, en virtud del cual se regula el flujo transfronterizo de datos de carácter personal. Ello tendrá su reflejo en los artículos 32 y 33 de la LORTAD, donde bajo el título de movimientos internacionales de datos, se preceptúa la prohibición de cesión de datos a países que no establezcan un nivel de protección igual al que establece la LORTAD, si bien se regulan excepciones. Con posterioridad, en 1995, la Directiva establecerá en su art. 25, idéntico contenido al respecto de la cesión internacional de datos a terceros países no integrantes de la Unión Europea, y que a su vez pasa a la Ley Orgánica 15/1999.

En definitiva, con estos cuatro ámbitos de protección, se establece la garantía, recogida ya en el ámbito nacional, de que los datos, salvo autorización expresa y concreta del interesado, no sufrirán un tratamiento indebido en otros países.

De capital importancia es referenciar la Directiva 95/46/CE del Parlamento Europeo y del Consejo, relativa a la protección de personas físicas en lo que respecta al tratamiento de datos personales y a la libre circulación de estos datos. Establece la Directiva, la necesidad de cumplir en un plazo de tres años (art. 32), la acomodación de las normativas nacionales al contenido de la misma.

Parece claro, que la Directiva viene a ampliar y concretar el ámbito que al respecto de la protección de datos ya había delimitado el Convenio de 1981. La disparidad legislativa de los Estados miembros, así como el desfase o la generalidad del Convenio, hacían necesaria una normativa más concreta y detallada, un substrato común en cuanto a la protección de datos y la preservación del derecho a la intimidad con un ámbito europeo o supranacional.

De esta forma, en 1995, el Parlamento Europeo y el Consejo de la Unión Europea pretenden garantizar por parte de los Estados miembros, "la protección de la libertades y los derechos fundamentales de las personas físicas, $y$, en particular, el derecho a la intimidad, en lo que respecta al tratamiento de datos personales» ${ }^{20}$.

Art. 1 de la Directiva 95/46/CE. 
En consecuencia, la normativa europea viene a establecer unos umbrales mínimos, que afortunadamente, y salvo en aspectos puntuales, nuestro ordenamiento jurídico ya establecía. Quizás la labor que mejor puede realizarse por la Unión Europea en el ámbito de la protección de datos, sea coordinar la actuación de los Estados miembros, y liderar una politica universal que ordene e impulse la actuación de órganos. Pese a ello, debemos de ser conscientes de la vigencia de la denominada sociedad globalizada, que sin duda, dificulta enormemente la posibilidad de control.

\section{APORTACIÓN DELTRIBUNAL CONSTITUCIONAL A LA INTERPRETACIÓN DEL ART. 18.4 CE}

Además de un detallado estudio normativo, no es en absoluto descartable en el ámbito del tratamiento de datos, y con objeto de un mejor entendimiento del contenido del art. 18.4 CE, el análisis de la jurisprudencia Constitucional. Esta ha de ir estableciendo sobre todo, los límites no prefijados por la legislación y sobre todo ha de determinar la interpretación correcta de la norma positiva que ofrece dudas tanto en su formulación como en su aplicación. Estas finalidades se han conseguido de distinto modo y en diverso grado por la jurisprudencia del Alto Tribunal. Destacamos a continuación las que a nuestro juicio han significado un aporte sustantivo, en la línea de ayudar al desarrollo e interpretación de la CE.

La primera sentencia a destacar es la 73/1982, de 2 de diciembre. Se establece en ella un primigenio concepto de derecho a la intimidad, manifestándose que aquélla, es un ámbito o reducto en el que se veda, que otros penetren y que no guarda por sí solo relación directa con la libertad de relacionarse con otras personas o derecho a tener amistades. Por su parte, la STC 110/1984 de 26 de noviembre constata que el avance de la tecnología actual y el desarrollo de los medios de comunicación de masas ha obligado a extender la protección de la vida privada más allá del aseguramiento del domicilio como espacio físico en que normalmente se desenvuelve la intimidad y del respeto a la correspondencia que es o puede ser medio de conocimiento de aspectos de la vida privada. Las injerencias en la intimidad no pueden ser arbitrarias o ilegales. Sólo cabe la intromisión por imperativos de interés público.

Como puede observarse, no es mucha la aportación jurisprudencial a estas fechas, pero se va tomando conciencia de las nuevas necesidades sociales. Un paso significativo lo constituye la STC 
142/1993, de 22 de abril, en la que se afirma que el atributo más importante de la intimidad, como núcleo central de la personalidad, es la facultad de exclusión de los demás, de abstención de injerencias por parte de otro, tanto en lo que se refiere a la toma de conocimientos intrusiva, como a la divulgación ilegítima de esos datos.

La STC 254/1993, de 20 de julio, es con mucho, una de las más significativas hasta la fecha en el ámbito que nos ocupa. En ella se establece al respecto del art. 18.4, que la Constitución ha incorporado una nueva garantía constitucional como respuesta a una nueva forma de amenaza concreta a la dignidad y a los derechos de la persona, en último término, de forma no muy diferente a como fueron originándose e incorporándose históricamente los distintos derechos fundamentales. Continúa afirmando la sentencia, que en el presente caso estamos ante un instituto de garantía de otros derechos, fundamentalmente el honor y la intimidad, pero también de un instituto que es, en sí mismo, un derecho o libertad fundamental, el derecho a la libertad frente a las potenciales agresiones a la dignidad y a la libertad de la persona, provenientes de un uso ilegítimo del tratamiento mecanizado de datos, lo que la Constitución llama "informática».

La constatación elemental de que los datos personales que almacena la Administración son utilizados por sus autoridades y sus servicios, impide aceptar la tesis de que el derecho fundamental a la intimidad agota su contenido en facultades puramente negativas, de exclusión. Las facultades precisas para conocer la existencia, los fines y los responsables de los ficheros automatizados dependientes de una Administración Pública, donde obran datos personales de un ciudadano, son absolutamente necesarias para que los intereses protegidos por el art. 18 C.E. y que dan vida al derecho fundamental a la intimidad, resulten real y efectivamente protegidos. Por ende, dichas facultades de información forman parte del contenido del derecho a la intimidad, que vincula directamente a todos los poderes públicos y ha de estar salvaguardado por este Tribunal, haya sido o no desarrollado legislativamente.

También es destacable la STC 143/1994, de 9 de mayo, puesto que viene a establecer que el derecho a la intimidad no es un derecho absoluto, como no lo es ninguno de los derechos fundamentales, pudiendo ceder ante intereses constitucionalmente relevantes, siempre que el recorte que aquél haya de experimentar se revele como necesario para lograr el fin legítimo previsto, proporcionado para alcanzarlo, y en todo caso, que sea respetuoso con el contenido esencial del derecho. 
Continúa manifestando el Tribunal que habría que convenir en que un sistema normativo que, autoriza la recogida de datos incluso con fines legítimos, y de contenido aparentemente neutro, no incluyese garantías adecuadas frente a su uso potencialmente invasor de la vida privada del ciudadano, a través de su tratamiento técnico, vulneraría el derecho a la intimidad de la misma manera en que lo harian las intromisiones directas en el contenido nuclear de ésta.

De capital importancia han sido las dos sentencias que comentamos a continuación, dado que resuelven sendos recursos de inconstitucionalidad planteados contra las dos leyes sobre protección de datos habidas en España hasta la fecha. La STC 290/2000, de 30 de noviembre, resuelve los recursos de inconstitucionalidad acumulados interpuestos por el Consejo Ejecutivo de la Generalidad de Cataluña, el Defensor del Pueblo, el Parlamento de Cataluña y D. Federico TrilloFigueroa Conde en representación de 56 Diputados del Grupo Parlamentario Popular, contra los artículos 6.2, 19.1, 20.3, 22.1 y 2, 24, 31, 39.1 y 2, 40.1 y 2, y Disposición Final Tercera de la Ley Orgánica 5/1992 de 29 de octubre, Reguladora del Tratamiento Automatizado de los Datos de Carácter Personal (en adelante LORTAD). Exponemos por separado el fundamento de cada uno de los recursos:

1. - La Generalidad de Cataluña reivindica las competencias de las Comunidades Autónomas para el ejercicio de las potestades y funciones de tutela sobre aquellos ficheros de titularidad privada creados por particulares en la consecución de actividades sobre las que la Comunidad Autónoma puede ostentar títulos competenciales, y sobre los creados por la Administración Local de Cataluña, y por consiguiente considera contraria a la Constitución la reserva de tales competencias con carácter exclusivo a la Agencia de Protección de Datos.

2. El Parlamento de Cataluña reprocha que la Ley Orgánica que desarrolla el artículo 18.4 CE no puede soslayar el marco de distribución de competencias; ni la interconexión entre los apartados 1 y 4 del artículo citado y el artículo $82.1 \mathrm{CE}$. En resumen el Parlamento de Cataluña deduce en su recurso que la Ley Orgánica, no configura título competencial alguno en favor del Estado.

3. El Defensor del pueblo arguye en su recurso que el artículo 19.1 de la LORTAD es inconstitucional por infracción de la reserva de ley dispuesta por el artículo 53.1 CE. Entiende el Defensor del Pueblo que las normas de creación, modificación o supresión de un fichero podrán tener carácter reglamentario; y, en segundo lugar, que esas normas pueden autorizar la cesión de datos sin necesidad de recabar el consentimiento del afectado, en contra, por tanto, de la regla gene- 
ral que sobre el particular establece el artículo 11 de la LORTAD. Esa cesión sin consentimiento del aludido por los datos de carácter personal supone, razona el defensor del Pueblo, un límite al derecho fundamental a la intimidad, y el artículo 19.1 de la LORTAD, autoriza a que dicho límite se concrete en una norma reglamentaria. El Defensor del Pueblo también impugna en su recurso de inconstitucionalidad los apartados 1 y 2 del artículo 22 de la LORTAD, en sus incisos «impida o dificulte gravemente el cumplimiento de las funciones de control y verificación de las Administraciones Públicas", "la persecución de infracciones... administrativas" y "ante razones de interés público o ante intereses de terceros más dignos de protección", por entender que lesionan el contenido del artículo 18.1 y $4 \mathrm{CE}$.

4. Por último, cincuenta y seis diputados pertenecientes todos ellos al Grupo Parlamentario Popular recurren en inconstitucionalidad los artículos 6.2, 19.1, y 22.1 y 2 de la LORTAD por entender que a su juicio se infringe el apartado 4 del artículo $18 \mathrm{CE}$, en relación con lo dispuesto en los artículos 10 y 105 b), también de la Constitución. Los términos que utiliza la Ley en los citados artículos, son conceptos jurídicos indeterminados que abandonan el límite al uso de la informática, y que no garantizan de forma efectiva el derecho fundamental a la intimidad. También entienden inconstitucional los diputados recurrentes la posibilidad que el artículo 11 establece de cesión de datos. Y por último, coinciden con el Defensor del Pueblo en la inconstitucionalidad del artículo 22 de la LORTAD.

Por providencia de 21 de diciembre de 1999 el TC hizo uso del artículo 84 de la LOTC, es decir oír a las partes acerca de la poșible pérdida sobrevenida de objeto de los recursos de inconstitucionalidad, dada la publicación en el BOE de 14 de diciembre de 1999 de la Ley Orgánica 15/1999, de 13 de diciembre de Protección de Datos de Carácter Personal (en adelante LOPD) dado que su disposición derogatoria única dejaba sin vigor la LORTAD.

El Parlamento de Cataluña considera que pervive la controversia competencial. El Consejo Ejecutivo de la Generalidad de Cataluña entiende que la nueva Ley Orgánica 15/1999 no altera en lo sustancial la controversia competencial, pues reproduce en buena parte los contenidos impugnados de la LORTAD y no sana los vicios en que incurría esta Ley. El Defensor del Pueblo comunica mediante escrito de 14 de marzo de 2000 que recurrirá en inconstitucionalidad diversos preceptos de la Ley Orgánica de 1999. Por su parte, el Grupo Parlamentario Popular había manifestado con anterioridad, y reitera ahora, su voluntad de desistir del recurso interpuesto contra la LORTAD. 
En sus fundamentos jurídicos elTC se plantea como primer punto a dilucidar, si procede examinar los recursos interpuestos teniendo en cuenta que el objeto de los mismos (LORTAD) es una norma derogada. Recurre para argumentar esta circunstancia el Tribunal a su propia jurisprudencia, en virtud de la cual, los preceptos objeto de un recurso de inconstitucionalidad referido al reparto competencial entre Estado y Comunidades Autónomas que hayan sido derogados al tiempo de resolver dicho recurso, producen la extinción del mismo por pérdida sobrevenida de su objeto. De esta forma, a juicio del Tribunal, el examen de la Disposición Derogatoria de la LOPD en relación con los preceptos impugnados, no pueden entenderse como vigentes. Pese a ello, el propioTribunal recuerda que subsiste la impugnación por razones competenciales respecto a los artículos 24,31 y 40.1 y 2 de la LORTAD, recogiendo asi lo alegado por el Consejo Ejecutivo de la Generalidad de Cataluña y el Parlamento de Cataluña. En resumen el Tribunal entiende que ha de pronunciarse en relación con las competencias que la LORTAD atribuye a la Agencia de Protección de Datos y al Registro General como órgano integrado en ésta, en lo relativo a los ficheros de titularidad privada.

Por lo manifestado, elTribunal desestima los recursos tanto del Consejo Ejecutivo de la Generalidad como del Parlamento de Cataluña, fundamentándolo en que la función de la Agencia de Protección de Datos tiene un carácter básicamente preventivo en orden a la protección de datos personales, tanto de los incluidos en bases de datos públicas, como privadas. Además elTribunal desestima su pretensión argumentado que los recurrentes no fundamentan su reivindicación en un título competencial específico del Estatuto de Autonomía de Cataluña. Además, el TC entiende que en el petitum de los dos citados recurrentes se está desvirtuando el bien jurídico constitucionalmente relevante, que no es otro que la protección de datos de carácter personal frente a un tratamiento informático. De lo que se desprende, que el objeto de la Ley cuyos preceptos se han impugnado, no es el uso de la informática, sino de la protección de datos personales.

De esta forma termina el Tribunal argumentando que «la garantía de los derechos fundamentales exigida por la Constitución así como de la igualdad de todos los españoles en su disfrute la que en el presente caso justifica que la Agencia de Protección de Datos y el Registro Central de Protección de Datos puede ejercer las funciones y potestades a las que antes se ha hecho referencia respecto a los ficheros informatizados que contengan datos personales y sean de titularidad privada radicados en Cataluña. Y, por ello han de decaer los reproches 
de inconstitucionalidad que los recurrentes han imputado a los artículos 24,31 y 40.1 y 2 de la LORTAD».

En lo relativo al resto de los contenidos de la LORTAD recurridos (artículos 6.2, 19.1, 20.3, 22.1 y 2, 39.1 y 2, y Disposición final tercera), elTribunal establece la pérdida sobrevenida del objeto de los recursos interpuestos.

A esta Sentencia el Magistrado Jiménez de Parga formula voto particular, en el que comparte el fallo, pero al que reprocha que debió afirmar de modo explícito que elTC reconoce y protege un nuevo derecho fundamental, de libertad informática, que no figura en la tabla de derechos del texto de 1978. De forma concreta afirma Jiménez de Parga que "a mi entender, una de las tareas importantes de los Tribunales Constitucionales es extender la tutela a determinadas zonas del Derecho no expresamente consideradas en las correspondientes Constituciones, cuando, como ocurre en el presente caso, es necesario hacerlo para que no queden a la intemperie, sin techo jurídico alguno, intereses esenciales de los ciudadanos». Reconoce el magistrado que esta labor en el ordenamiento jurídico español es más difícil que en otros, pero justifica su necesidad en dos argumentos:

1. ${ }^{\circ}$ A juicio del magistrado existen derechos no recogidos en la Constitución (no escritos), y es labor de la jurisprudencia tutelar esos nuevos derechos, $y$ utiliza como ejemplo el sistema constitucional norteamericano. En otras ocasiones, como en Italia (art. 2) o en Alemania (art. 2.1), sus Constituciones mediante determinados preceptos, han facilitado la inclusión de nuevos derechos. A juicio de Jimenez de Parga, nuestra CE no tiene una cláusula abierta como remate o coronamiento de la lista de derechos fundamentales, lo cual justifica la necesidad de configurar derechos fundamentales a través de la jurisprudencia.

2. Nos recuerda el magistrado, que la STC 254/1993, en su f. j. 6, mencionó, por primera vez en nuestra jurisprudencia, la libertad informática, entendida como un derecho fundamental en sí mismo. Que tiene su fundamento en el art. 10.1 CE, ya que es un derecho inherente a la dignidad de la persona. También son preceptos que facilitan la configuración constitucional de la libertad informática, los contenidos en los artículos 18.1 y 20.1, así como los Tratados y Acuerdos internacionales. Acaba resumiendo que «los cimientos constitucionales para: levantar sobre ellos el derecho de libertad informática son más amplios que los que proporciona el art. 18.4 CE».

Como hemos apuntado con anterioridad, la jurisprudencia más reciente se concreta en la STC 292/2000, de 30 de noviembre. En la 
misma fecha que el TC resuelve el recurso de la LORTAD, resuelve el interpuesto por el Defensor del Pueblo contra la Ley Orgánica 15/1999, de Protección de Datos de Carácter Personal. El Defensor del Pueblo reitera los argumentos de insconstitucionalidad que reprochó a la LOR$T A D$, es decir, el art. 21.1 relativo a la «comunicación de datos entre Administraciones Públicas" y art. 24.1 y 2 , relativo a "otras excepciones a los derechos de los afectados». En virtud del primero de los artículos citados, a juicio del Defensor del Pueblo, se posibilita que puedan hacerse cesiones de datos entre Administraciones Públicas para fines distintos a los que motivaron su recogida, a la vez que el titular de esos datos no sea informado, cuando se recaban, de la posibilidad de dicha cesión, al no estar prevista en la norma que crea y regula el fichero. Por último, también entiende inconstitucional el art. 20.1, porque la autorización para efectuar esas cesiones puede contenerse en una norma de rango inferior a la ley.

En relación con el art. 24. 1 y 2, argumenta el Defensor del Pueblo que son contrarios al art. 18.1 CE, pues no respetan el contenido esencial de los derechos fundamentales al honor y a la intimidad personal y familiar. El inciso primero del art. 24 de la LOPD, exime, a juicio del Defensor del Pueblo, a la Administración de cumplir con las obligaciones de información y advertencia que establece el art. 5.1 y 2 de la misma Ley, si tal cosa pudiera impedir o dificultar gravemente las funciones de control y verificación de las Administraciones Públicas o cuando afecte a la persecución de infracciones administrativas. Esta circunstancia privaría al los individuos de sus derechos de acceso a los datos en poder de la Administración, y en su caso a la obligada rectificación y cancelación.

Para mejor comprensión de las argumentaciones del Defensor del Pueblo, reproducimos el contenido de los artículos impugnados, resaltando en negrilla lo que a su juicio esta afectado de inconstitucionalidad.

\section{Art. 21.1}

"Los datos de carácter personal recogidos o elaborados por las Administraciones Públicas para el desempeño de sus atribuciones no serán comunicados a otras Administraciones Públicas para el ejercicio de competencias diferentes o de competencias que versen sobre materias distintas, salvo cuando la comunicación hubiere sido prevista por las disposiciones de creación del fichero o por disposición de superior rango que regule su uso, o cuando la comunicación tenga por objeto el tratamiento posterior de los datos con fines históricos, estadísticos o científicos». 


\section{Art. 24}

1. "Lo dispuesto en los apartados 1 y 2 del art. 5 no será aplicable a la recogida de datos cuando la información al afectado impida o dificulte gravemente el cumplimiento de las funciones de control y verificación de las Administraciones Públicas o cuando afecte a la Defensa Nacional, a la seguridad pública o a la persecución de infracciones penales o administrativas".

2. "Lo dispuesto en el art. $15 y$ en el apartado 1 del art. 16 no será de aplicación si, ponderados los intereses en presencia, resultase que los derechos que dichos preceptos conceden al afectado hubieran de ceder ante razones de interés público o ante intereses de terceros más dignos de protección. Si el órgano administrativo responsable del fichero invocase lo dispuesto en este apartado, dictará resolución motivada e instruirá al afectado del derecho que le asiste a poner la negativa en conocimiento del Director de la Agencia de Protección de Datos o, en su caso, del órgano equivalente de las Comunidades Autónomas».

De esta forma, a juicio del Defensor del Pueblo, la cuestión se centra en entender que los derechos del ciudadano alcanzan a la información, rectificación y cancelación, y éstos son parte integrante de un genérico derecho a la autodeterminación informativa recogido en el art. 18.4 CE, y en el apartado primero del citado artículo. Consecuencia de ello es también que la habilitación que el art. 24.1 y 2 de la LOPD otorga a la Administración Pública, lesiona aquellos derechos.

Separa en sus fundamentos jurídicos el TC la argumentación al respecto de inconstitucionalidad, el art. 21 y el art. 24, por ello nosotros, los analizamos también por separado.

a) Respecto del primero de los artículos, elTC argumenta que "la función del derecho fundamental a la intimidad del art. 18.1 CE es la de proteger frente a cualquier invasión que pueda realizarse en aquel ámbito de la vida personal y familiar que la persona desea excluir del conocimiento ajeno y de las intromisiones de terceros en contra de su voluntad». En cambio, el derecho fundamental a la protección de datos persigue garantizar a esa persona un poder de control sobre sus datos personales, sobre su uso y destino, con el propósito de impedir su tráfico ilícito y lesivo para la dignidad y derecho del afectado". Continúa afirmando elTC, "de este modo, el objeto de protección del derecho fundamental a la protección de datos no se reduce sólo a los datos íntimos de la persona, sino a cualquier tipo de dato personal, sea o no íntimo, cuyo conocimiento o empleo por terceros pueda afectar a sus derechos, sean o no fundamentales, porque su objeto no es sólo la intimidad individual, que para ello está 
la protección del art. 18.1 CE otorga, sino los datos de carácter personal». (f. j. 6).

Más adelante, en el f. j. 7, el Tribunal apostilla que «son elementos característicos de la definición constitucional del derecho fundamental a la protección de datos personales los derechos del afectado a consentir sobre la recogida y uso de sus datos personales y a saber de los mismos. Y resultan indispensables para hacer efectivo ese contenido el reconocimiento del derecho a ser informado de quién posee sus datos personales $y$ con qué fin, y el derecho a poder oponerse a esa posesión y uso requiriendo a quien corresponda que ponga fin a la posesión y empleo de los datos".

b) Por lo que hace referencia al art. 24 de la LOPD, entiende el TC que el empleo en su apartado primero de la expresión ufunciones de control y verificación", abre un espacio de incertidumbre tan amplio que provoca una perversa consecuencia. Así, al habilitar la LOPD a la Administración para que restrinja derechos fundamentales invocando semejante expresión está renunciando a fijar ella misma los límites, apoderando a la Administración para hacerlo. Ello deja al ciudadano en palabras del Tribunal en la "más absoluta incertidumbre» (f.j. 17).

Igual reproche merece el apartado segundo del art. 24 LOPD, pues encierra un grado de incertidumbre aún mayor, pues como afirma elTC, "el interés público en sancionar infracciones administrativas no resulta, en efecto, suficiente, como se evidencia en que ni siquiera se prevé como límite para el simple acceso a los archivos y registros administrativos contemplados en el art. 105 b) CE (f. j. 18).

Consecuente con estas argumentaciones, el TC estima las pretensiones del Defensor del Pueblo y declara contrarios a la CE y nulo, el inciso "cuando la comunicación hubiere sido prevista por las disposiciones de creación del fichero o por disposición de superior rango que regule su uso", del apartado primero del art. 21 de LOPD. También declara contrarios a la CE y nulos los incisos "impida o dificulte gravemente el cumplimiento de las funciones de control y verificación de las Administraciones Públicas" y "o administrativas", del apartado primero del art. 24. Por último, declara nulo en su totalidad, el apartado segundo del art. 24 de la LOPD.

\section{CONCLUSIONES}

Para finalizar este balance constitucional, conviene hacer resumen de lo más importante en relación con el tema que nos ocupa. 
1. ${ }^{\circ}$ Es justo reconocer, en un balance al respecto del art. 18.4 $\mathrm{CE}$, que ofrece un contenido de anticipación y previsión. EI constituyente supo ver en 1978 las posibilidades técnicas de comunicación, a la vez que intuía las consecuencias negativas que ello podía tener en la eficaz garantía de los derechos y libertades. Creo conveniente advertir al lector que nuestra Constitución cumple ahora 25 años de vigencia, y que si aplicamos esta medida a la norma jurídica dice poco, pero si lo trasladamos al ámbito de la ciencia, la tecnología o las comunicaciones, es un dato muy a tener en cuenta. Por todo ello, hay que reconocer que nuestra Constitución se pone a la cabeza de los reconocimientos del mismo rango jerárquico, en el ámbito de la protección de datos.

2. No puede obtenerse igual valoración del desarrollo legislativo del art. 18.4. Tuvieron que pasar 14 años para que contásemos con una norma de desarrollo. En ese periodo se acudía como hemos visto a la regulación civil, y a una contradictoria jurisprudencia, en un principio del Tribunal Supremo, y con posterioridad del Tribunal Constitucional. La LORTAD vino a ordenar en gran medida un ámbito de la relaciones sociales, necesitado de principios rectores y de mecanismos de garantía de los derechos esenciales para la dignidad y el libre desarrollo de la personalidad.

Pero tampoco podemos considerar a esta norma como la panacea, $y$ quizás no sea tan imputable sus lagunas al legislador, y sí más bien al Tribunal Constitucional, que a mi juicio ha tardado demasiado en entender la importancia de la protección de datos. Parece desde todo punto de vista jurídico improcedente, que los recursos interpuestos contra la LORTAD, vieran su resolución un año después de derogada la Ley, y casi ocho años después de interpuestos ${ }^{21}$. Quizás sea consecuencia ello, de la ausencia de un criterio por parte del Tribunal Constitucional al respecto del tratamiento de datos en relación con derechos tan sustantivos como la libertad de expresión o los derechos de la personalidad.

Pero también es justo reconocer que el Tribunal Constitucional ha enmendado esta línea de actuación, de forma que el recurso de inconstitucionalidad interpuesto contra la vigente Ley Orgánica de Pro-

21 STC 290/2000, de 30 de noviembre. 
tección de Datos, se resolvió antes de transcurrido un año de vigencia de la misma22.

Creo en última instancia, que la labor delTribunal Constitucional es capital en esta parcela de los derechos fundamentales, y quizás lo más importante, que el citado Tribunal tiene conciencia de ello.

3. Otra conclusión que conviene apuntar, es la evolución que necesita todo derecho. Si en 1978, se acierta a reconocer y garantizar un ámbito de protección, y sus exigencias evolucionan de forma rápida, no puede exigirse al ordenamiento jurídico otra cosa que no sea atender esa necesidad, $y$ este trasiego se ha conseguido, a mi juicio, de forma satisfactoria.

Existe el reconocimiento jurídico, tanto el ciudadano, como los operadores jurídicos y sociales tienen conciencia de la necesidad de la garantía y ejercicio efectivo de la protección de datos. Ahora bien, como hemos apuntado, existe un inconveniente, que no es otro que el desfase entre posibilidad técnica y garantía jurídica. En corregir las lagunas que esta circunstancia produzca, habrá de poner empeño el legislador, así como los encargados de garantizar la vigencia de la CE. Pero también conviene mirar atrás, y ver lo conseguido, y la valoración de la vigencia y desarrollo del art. 18.4 CE, ha de ser en todo caso positiva. 